\title{
Contribution of modern social networks in building social integration in public Universities in Uganda.
}

\author{
Peter Nareeba, Dr. Anthony Ichuloi PhD, Prof. Edmond Were PhD \\ Department of sociology, Kisii University (Kenya) \\ Department of Philosophy and Religious Studies Kisii University \\ Political science department Kisii University (Kenya)
}

\begin{abstract}
The study investigated the Contribution of modern social networks in building social integration in five public Universities in Uganda with a target population of 266 students' groups. It employed multi-stage sampling technique, comprising of purposive and simple random sampling to select 57 students' groups with a total of 456 respondents. Data collection tools comprised of questionnaires and interview schedules. The findings indicate that the most interrogating issue was that a majority of the respondents revealed that social media has negative effects on social integration. The results revealed that unity among students enables them acquire a sense of belonging as a body of students, hence enhancing social cohesion within the social groups. WhatsApp was ranked at position one with a mean grade of 1.17 with the percentage of $86.1 \%$ ranking it at first position. It was closely followed by Facebook with rank two with a mean grade of 1.66 with $38.5 \%$ ranking it at second position

The study therefore recommends universities' administration to formulate accommodative policies that properly regulate the use of social network platforms. The study also recommended public universities to strengthen organs and institutions that deal with proper management of social networks in their instructions
\end{abstract}

\subsection{Introduction}

Social network podiums bring out the fact that individuals are not living and acting in isolation, rather are socially related. In today's global and technological society, social network platforms whether conventional (church organizations, students' associations, etc.) or technologically determined (social media platforms such as Facebook, WhatsApp, Google Plus, Blogs, Twitter, Instagram, MySpace, YouTube, etc.) have a major influence on human relationships and integration, in such a way that they enable members of society to engage with each other in fundamentally new and different ways (Kuppuswamy and Narayan, 2010).

The modern technological network platforms included WhatsApp, twitter and Facebook. Availability of internet and smartphone/ICT centres makes the interaction among students accessible both in the campus and out of the campus. These modern means of social interactions (social network platform) are attracting attention of many students due to various reasons which the research sought to find. Social media according to Andreas Kaplan refers to the means of interactions among people in which they create, share and/or exchange information and ideas in virtual communities and network. It creates the opportunity to network with other members who share similar or common interest, dreams and goals. As it is common knowledge, with the social media network like WhatsApp, people initiate and build strong business partnerships in any part of the world without meeting each other. Dumbrell and Steele (2014) presented an informal knowledge management framework and established that social media technologies are for public peer-to-peer sharing, content evaluation amongst peers, etc., all facilitated by the "push" nature of these systems.

The point is that social media platforms have greatly influenced today's society such that social relationships are re-defined to enable individuals to share their everyday life in their communities and facilitate the social interactions. Their influence has become a fundamental part of peoples' daily life experiences all over the world. In the educational and learning environment, particularly the larger university communities, social 
network platforms contribute a lot to the manner in which students integrate, thereby forming their relational environment, which influences their identity and self-image.In order to establish the most employed modern technological social media platform, the researcher sampled group members. They were asked to rank the platform they frequently use with the scale of rank one to rank eight. In this study the contribution was classified into two, that is positive and negative contribution of modern social networks in building social integration.

\subsection{Literature review and knowledge gap}

This Study is guided by various theories that informed and demonstrated understanding of the importance and challenges of social network platforms to students in public universities. This included the functionalist and gratification theory, social network theory for formal and informal social networks, social integration theory for dependent variable and social capital theory for social support.

From the literature review it is argued that social networks are potentially correlated with key social integration outcomes. However, the majority of researches have tended to emphasize outcomes such as academic and psychological adjustment and well-being, while undermining the social aspects that bring social integration: social capital, social cohesion, social protection and sense of belonging.

Another gap within the literature on social networks and social integration is that, the studies provide very little insight into the ways in which specific social networks such as participation in informal and formal networks affect various ways of social integration during college. This is because, much of the existing theoretical research on social networks has been centred on social network sites and their practical operations but not their social effects particularly on social integration. This gap in the literature presents the need for more empirical studies to complement the theoretical literature. Furthermore, most studies for social networks, particularly formal networks focus on developed countries, while undeveloped countries are seen as mere importers and consumers of such networks. Therefore, it is the intent of this study to fill the above identified gaps by assessing the influence of social networks platforms in building social integration in public university communities in Uganda.

\subsection{Methodology}

The study used $21.4 \%$ of the target population; which translates into the sample size of 57 student groups who were selected from the general total estimated population of 266 student groups. $\frac{21.4}{100} \times 266=57$ student groups. The intended sample size was 57 groups comprising three group leaders (Chairperson, secretary and treasurer) and five group members.

The study employed multi-stage sampling technique comprising of purposive and simple random sampling. This was convenient for selecting the participants for this study and it ensured a fairly equal representation of the social network platform variables that determined social integration of students and staff; it also gave credibility and representativeness for accurate generalization of the results. Thiswas done in five (5)public universities in Uganda for equal representation of the five regions in the country: Makerere University (central), Busitema University (east), Mbarara University (West), Kabale University (South) and Gulu University (North).

The researcher selected the sample groups using simple random sampling such that within each university, a selection of students' leaders and membersas a sample was done by writing out the names of the staff in piece of paper which was folded and put in a basket and well mixed. The researcher then selects some for consideration in data collection and data analysis.

Table 1: Sample Size of the Groups

\begin{tabular}{|l|c|c|c|c|c|}
\hline \multirow{2}{*}{ University } & \multicolumn{2}{|c|}{ Groups } & \multicolumn{3}{c|}{ Respondents } \\
\cline { 2 - 6 } & Target & Sample & Members & Leaders & Total \\
\hline Makerere University & 75 & 23 & 115 & 69 & 184 \\
\hline Busitema University & 22 & 7 & 35 & 21 & 56 \\
\hline Mbarara University & 39 & 12 & 60 & 36 & 96 \\
\hline
\end{tabular}




\begin{tabular}{|c|c|c|c|c|c|}
\hline Kabale University & 17 & 5 & 25 & 15 & 40 \\
\hline Gulu University & 34 & 10 & 50 & 30 & 80 \\
\hline Total & $\mathbf{1 8 7}$ & $\mathbf{5 7}$ & $\mathbf{2 8 5}$ & $\mathbf{1 7 1}$ & $\mathbf{4 5 6}$ \\
\hline
\end{tabular}

\section{Source: Researcher (2017)}

Apart from students, the study also sampled administrative staff and teaching staff through purposive sampling technique and stratified random sampling technique. A total of 32 staffs were select 4 from each university. This comprised of dean of student affairs and chaplain to represent religious leaders was select using purposive sampling technique. These two staffs are vital in the formation, organization and operation of students' groups within the university. The study also selected two respondents from other groups that exist within the university. The researcher first stratified them into two categories; sports/games club and non- sports/games club. From each group, simple random sampling technique was used to select one respondent (patron). The inclusion of patron was vital as they actas a link between administration and students and they also offer guidance to group leaders.

\subsection{Data}

This study used primary data collected from the field. Influenced by Mugenda and Mugenda (1999), who observes that a researcher should design instruments that will help to collect the necessary information as per the type of research that is undertaken, this study therefore, employed questionnaire and interview as reliable and convenient instruments of study. The structured questionnaires were administered directly to the respondents who were committed to fill them on their own to give required necessary data for the study. Interview schedule is a set of structured questions written down, that the interviewer asks during the interview. The use of this instrument was convenient for this study since the research aimed at describing the nature and influence of social network platforms on the students about social integration process in the universities; further it provided a reliable basis for empirical literature for the generalization of the research outcomes regarding social network platforms.

\subsection{Study findings}

The study investigated the Contribution of modern social networks in building social integration in public Universities in Uganda.In a summary form, the sampled respondents were asked to state the effect of modern social media on social integration of the students in the implied universities. To do that the researcher classified the responses into two: positive and negative effects of modern social media on students' social integration illustrated in figure 1

\section{responces}

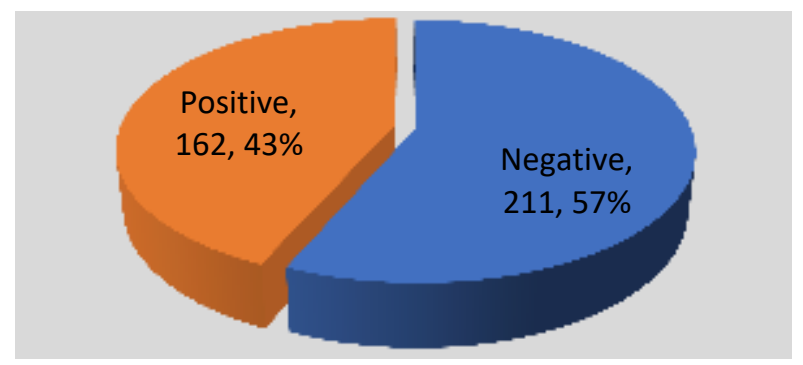

\section{Figure 1: Contribution of Modern Social Networks in Building Social Integration Source: Field Data (2018).}

From the findings in the graph above, the most interrogating issue was that a majority of the respondents revealed that social media has negative effects on social integration as shown by $57 \%$ (211) while those sampled group members who indicated it has positive effects were fewer, comprising of $43 \%$ (162) of the sampled population. The results for negative effects of technological social platforms were further broken down as shown in Table 2. 
Table 2: Negative of Modern Platforms

\begin{tabular}{|l|l|l|}
\hline Negative Effect & Frequency & Percentage \\
\hline Rivals with other associations & 204 & 54.69 \\
\hline Closed inward integration for cultural group & 189 & 50.67 \\
\hline Divisive political gains & 188 & 50.4 \\
\hline Hatred toward other ethnic groups & 178 & 47.72 \\
\hline Misunderstanding among students & 144 & 38.61 \\
\hline Discrimination among students & 67 & 17.96 \\
\hline
\end{tabular}

\section{Source: Field Data (2018)}

From Table 2 above, $54.69 \%$ (204) of the sampled group members revealed that social media platforms increase rivals and tensions with other students' associations, especially among ethnic groups as each group wants to show their might over others. This was more supported by the $47.72 \%$ (178) of the sampled students who indicated that social media has led to hatred toward other ethnic groups in the university as each group wants to outdo each other. The profound effect of this is the misunderstanding among students threatening social relation and unity in the universities.

Similarly, $50.4 \%$ (188) of the respondents revealed that social media platforms have taken advantage of the social media to advance their divisive leadership politics, thereby increasing wrangles among students. Instead of uniting students, the ambitious politically motivated leaders have used social media to marshal support from their ethnicity or region further dividing students. While half $50.67 \%$ (189) of the respondents revealed that modern social media platforms have led to closed ethnic groups which make it difficult to others not belonging to that cultural group.Lastly, some students $17.96 \%$ (67) indicated that all students are not in social media group hence leading to discrimination of students who do not fall in any group especially those who are broke.

From the findings, as supported by Frees and Kessler (2004), technology based platforms are potential means to bring students together,including the enhancement of academic goals. Above it has been explained that such platforms make communication easier among students and even students with their lecturers and administrators (Nicholson, 2002). They have enhanced learning in an online version. Technologically motivated platforms provide an important new interface for student teacher contact, which in turn serves as a basis for building relationships.

In outlining the advantages of modern social networks, the researcher went further to classify the results as shown in the table 3:

Table 3: Positive Effects

\begin{tabular}{|l|l|l|}
\hline & Participants & Percentage \\
\hline Unity & 132 & 35.39 \\
\hline Networking & 125 & 33.51 \\
\hline Share idea & 123 & 32.98 \\
\hline Discipline & 101 & 27.08 \\
\hline Cultural diversity & 98 & 26.27 \\
\hline Social relations & 89 & 23.86 \\
\hline Link student with administration and lecturers & 78 & 20.91 \\
\hline Cooperation among social groups & 45 & 12.06 \\
\hline
\end{tabular}

Source: Field Data (2018)

From Table 3, $35.39 \%$ (132) of the sampled respondents indicated that social media has resulted to unity in the university while $33.51 \%$ (125) indicated it enhances networking. The results also revealed that $32.98 \%$ (123) it has enable sharing if idea. Other positive effects were $27.08 \%$ (101) discipline, $26.27 \%$ (98) cultural diversity, $23.86 \%$ (89) social relations, $20.91 \%$ (78) link student with administration and lecturer and $12.06 \%$ (45)cooperation among social groups in the university was the least effect.

The results revealed that unity among students enables them acquire a sense of belonging as a body of students, hence enhancing social cohesion within the social groups. This sense of belonging helps to avert 
students' unrests in a manner that it is possible to lick out any possible planned unrest through social media. The students are also allowed to express their problems and issues to the administration, which allows universities to properly handle them on time. For personal wellbeing, students have used social media to reduce stress, encourage togetherness and bond more people together thereby promoting interpersonal relationship. These technological platforms, especially Facebook and WhatsApps Groups, therefore, have the potential for group collaboration, promotion of social interaction, promotion of interaction between students and teachers, and expansion of learning beyond the classroom (Fewkes and McCabe, 2012).

\section{Table 4: Ranking of Technological Social Platforms}

\begin{tabular}{|l|l|l|}
\hline Platform & Overall Mean Rank & \multicolumn{1}{c|}{ Rank } \\
\hline WhatsApp & 1.17 & 1 \\
\hline FaceBook & 1.66 & 2 \\
\hline Twitter & 3.29 & 3 \\
\hline Instagram & 3.77 & 4 \\
\hline Snapchat & 5.22 & 5 \\
\hline Google+ & 6.12 & 6 \\
\hline MySpace & 6.55 & 7 \\
\hline
\end{tabular}

\section{Source: Field Data (2018)}

From Table 4, WhatsApp was ranked at position one with a mean grade of 1.17 with the percentage of 86.1\% ranking it at first position. It was closely followed by Facebook with rank two with a mean grade of 1.66 with $38.5 \%$ ranking it at second position. Twitter was ranked at position three with $72.2 \%$ (197) at position three and $22.3 \%$ (61) at rank3. Instagram was ranked at position four with a mean grade of 3.77 of $72.2 \%$ (197) rank at 4. Snapchat was ranked at position 5 with mean rank of 5.22 of which 75.1\% (205) at position five. Google+ was ranked at position 6 with mean rank of 6.12 of $68.1 \%$ (186) at rank 6. MySpace was least used with mean rank of 6.55 of which $72.2 \%$ (197) rank it at position seven. According to global statistics (August 2018), Facebook leads with over 2.0 billion users, whatsapp has 1.5 billion, instagram 1 billion, twitter 336 million, Google+ 327 million users, snapchat 255 million and MySpace came last 30 million users. Facebook, with more than 2.0 billion monthly active users, remains the world's most popular social network. This ranking was informed by the gratification theory. The students as users, therefore, are greatly influenced by this theory since they play an active role in choosing and using a particular social media platform that best fulfil the needs of students (Blumler and Katz, 1974) as indicated in the table above.

The informants expressed that the use of modern technological social network platforms, particularly WhatsApp, Facebook or Google+ enable to exchange information between friends and family to the level of posting photos, status sharing and social games. Other social networks like Twitter are all about rapid communication. These platforms and their frequent use they give an influential and strong social impact. The blurring between offline and virtual life as well as the concept of digital identity and online social interactions are some of the aspects that have emerged in recent discussions.

The interviews with group leaders revealed that WhatsApp is growing fast among students groups due to its ability as instant messenger and therefore able to connect them instantly in their attempt to answer their everyday concerns like uploading of group and individual photos, class notes (in PDF, word or any other format), sharing of encouraging and comforting information in times of sorrow, distress, fast means for soliciting and collecting of financial help, group chats, etc. They further expressed that it has made it easy for them to send message at very low cost and sometimes. It is a platform that has given both real and virtual community and community relationships, within and outside of the universities' premises.

Other technological social spaces are those of live chats where several social media sites have chat clients that enable members to chat with each other. There is also Direct Messaging facility, where several social media sites provide direct messaging facility to their members. This allows members to send private messages, which can be read or viewed only by those for whom the message is intended. There also exists the Provide tagging alerts platforms such that most social media sites alert members through e-mail or in site notifications whenever they are tagged in a message or in a photograph and enable members to create unique 
pages. On some social media sites, members can create theme-based pages which enable them to post articles or photographs related to a theme. The pages can also be used to promote businesses. Those who use Facebook use it mostly to engage with each other because of the option to "comment" which allows different people share their opinions on one Facebook page.

Social media also comes with some anonymity factor whereby users can easily assume personalities and names that do not exist hence it becomes easy for them to do what they want on social media without revealing their true identity.

\section{Informants' Views on the Benefits of Sharing Information}

The sampled group members were asked to state their level of agreement on the benefits of the above ranked social platforms with their related shared content.

\section{Series 1}

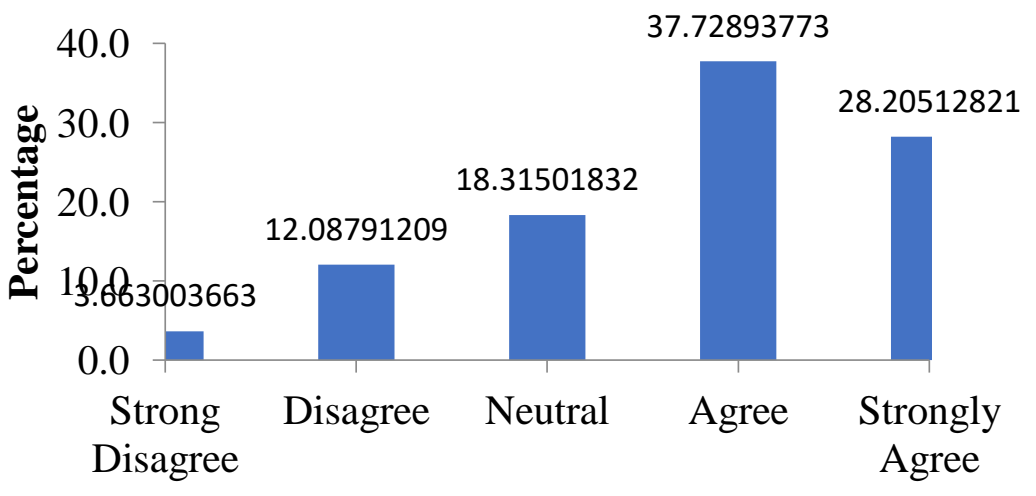

Figure 2: Sharing of Messages

Source: Field Data (2018)

From Figure 2, 37.73\% (103) agreed that messages shared in the group are mainly beneficial to the group members and $28.21 \%$ (77) strongly agree on the same. However, $15.8 \%$ of the sampled respondents did not confirm that messages shared in the group are mainly beneficial to the group members. The central issue was that majority of the informants agree or see it that modern technological social platforms are useful to social relationships and the sharing of information (Paroutis and Saleh, 2009).

\section{The Social Nature of Information Shared}

The researcher established that the majority of the university students agree and use modern social media platforms. On that basis, the research sought to establish the kind of information shared through the above social platforms. To do that the researcher sampled groups, where they were requested to rank the nature of message or information shared in relation to particular platforms. They were to do this by the order rank from rank one to rank eight. The results are as shown in Table 5:

Table 5: Rank of Nature of Messages in Social Media Platform

\begin{tabular}{|l|l|l|}
\hline Message & Overall Mean Score & Rank \\
\hline Politics & 1.44 & 1 \\
\hline Gossip & 2.06 & 2 \\
\hline Love & 3.27 & 3 \\
\hline Spiritual & 3.56 & 4 \\
\hline Sports & 5.21 & 5 \\
\hline Hate & 6.10 & 6 \\
\hline Academic & 7.06 & 7 \\
\hline Health & 7.39 & 8 \\
\hline
\end{tabular}

Source: Field Data (2018) 
From Table 5, politics was ranked at position one with mean rank of 1.44 of which 86.4 (236) ranked at position one. Second in rank was gossip with a mean rank of $2.0698 .9 \%$ (270) ranking at position 1. Third in rank was love message with mean rank of 3.27 of which $76.9 \%$ ranked it in position three. Fourth in rank was spiritual message with mean rank of 3.56 of which $59.0 \%$ rank it at position four. Academic message was ranked at position five with mean rank of 4.06 with $57.5 \%$ ranking it at position five. This section was guided by both the functional and gratification theories to explain the nature of messages and information shared by university students in Uganda in Social Media platform.

\subsection{Recommendations}

Based on the study findings, the researcher makes the following recommendations

- Cooperation among social groups in the university was the least effect so universities must always encourage cooperation within the social groups so as to promote more learning

- teaching staff and students can be put in one social group so as they can share their views, grievances on the topics of interest

- Universities should make internet access 24 hours available to the leaners.

Acknowledgement: My great thanks are addressed to my beloved wife Annet Kwarija and my Son Mark Williams Nareeba who continuously kept a check and gave me the momentum that enabled me achieve academic dream. My recognition is addressed to Management of kabale University who gave me constant reminders and encouragement to either publish or perish. My sincere thanks go to my supervisors Professor Edmond Were and Dr. Ichuloi Anthony for persistently offering me technical research guidance until this study was completed. Finally, I thank my brothers Gariho Medad, Frank Turyatunga, Micheal Taremwa, Fred Mwesigwa together with peace Karegyeya on their regular concern and checks during the time I carrying out this study

Copy right: All rights are reserved. No part of this work may be reproduced or utilized, in any form or by any means, electronic or mechanical, including photocopying, recording or by any information storage or retrieval system without prior written permission of the author or Kisii University. Copy rights reserved by the author with first publication rights granted to the journal.

\subsection{References}

[1] Dumbrell, D., \& Steele, R. (2014). Social media technologies for achieving knowledge management amongst older adult communities. Procedia-Social and Behavioral Sciences, 147, 229-236.

[2] Fewkes, A. M., \& McCabe, M. (2012). Facebook: Learning tool or distraction?. Journal of Digital Learning in Teacher Education, 28(3), 92-98.

[3] Frees, S., \& Kessler, G. D. (2004, October). Developing collaborative tools to promote communication and active learning in academia. In 34th Annual Frontiers in Education, 2004. FIE 2004. (pp. S3B-20). IEEE.

[4] Kuppuswamy, K., \& Narayan, P. S. (2010). The impact of social networking websites on the education of youth. International journal of virtual communities and social networking (IJVCSN), 2(1), 67-79.

[5] Mugenda, O. M. and Mugenda, A. G. (1999).Research Methods. Quantitative and Qualitative Approaches. Nairobi: Acts Press.

[6] Nichols, M. (2002). Student perceptions of support services and the influence of targeted interventions on retention in distance education. Distance education, 31(1), 93-113.

[7] Paroutis, S., \& Al Saleh, A. (2009). Determinants of knowledge sharing using Web 2.0 technologies. Journal of knowledge management, 13(4), 52-63. 